\title{
Buğday Kepeği Kullanılarak Crystal Violet (CV) Boyar Maddesinin Giderimi: Kinetik Çalışmalar
}

\author{
Neșe ERTUGAY
}

Erzincan Binali Yıldırım Üniversitesi, Mühendislik Fakültesi, İnşaat Mühendisliği Bölümü, Erzincan

Geliş / Received: 20/03/2018, Kabul / Accepted: 13/09/2018

\section{Öz}

Boyar maddelerin yaygın kullanımından kaynaklanan boyalı atık suların arıtılması önemli bir çevre sorunudur. $\mathrm{Bu}$ nedenle boyar madde içeren tekstil endüstrisi atık sularından renk giderim prosesleri ekolojik açıdan önem kazanmaktadır. Günümüzde büyük hacimli atık sulardaki boyar maddelerin etkili ve ekonomik bir şekilde giderilebilmesi için alternatif yöntemlere gereksinim vardır. Bu çalışmada tekstil atık sularında yaygın olarak bulunan Crystal Violet (CV)'in buğday kepeği üzerine adsorpsiyonu incelenmiştir. Kepeğin CV boyar maddesinin adsorpsiyonu üzerinde etkilerini belirlemek için; farklı başlangıç boya konsantrasyonları, $\mathrm{pH}$ değerleri, adsorbent konsantrasyonları ile sıcaklık parametreleri denenmiş ve optimum koşullar sağlanmıştır. En yüksek giderimin doğal $\mathrm{pH}$ (6.24)'da olduğu gözlemlenmiștir. Adsorbent miktarı belli bir değere kadar arttıkça boyar madde giderimi de artmıştır. Ayrıca, adsorpsiyonun 120. dakikada dengeye geldiği ve boyar madde konsantrasyonu arttıkça giderim veriminin düştügü görülmüştür. Bununla birlikte, sıcaklığın $25^{\circ} \mathrm{C}$ 'den $45^{\circ} \mathrm{C}$ 'ye arttırılması boyar madde giderimini artırmıştır. Bunun yanında deneysel verilerin Langmuir ve Freundlich izotermler ile yalancı birinci ve ikinci derece kinetik modellere uygunluğu araştırılmıștır. Bu modellere ait parametreler ile adsorpsiyon prosesine ait termodinamik parametreler hesaplanmıştır. Karakterizasyon çalışmaları kapsamında buğday kepeği için adsorpsiyon öncesi ve sonrası Fourier Transform Infrared (FTIR) ve Scanning Electron Microscopy (SEM) analizi yapılarak biyosorpsiyon mekanizmasındaki fonksiyonel gruplar incelenmiş ve biyosorpsiyon sonrası oluşan yapısal değişikliklerin varlığı görülmüştür.

Anahtar Kelimeler: Adsorpsiyon, Boya, İzoterm, Kinetik, Tekstil Atık Suları

\section{The Removal of Crystal Violet (CV) Dyestuff by Wheat Bran: Kinetic Studies}

\begin{abstract}
Treatment of waste water containing dye from widespread use of dyestuff is an important environmental issue. For this reason, color removal processes from waste water of the textile industry containing dyestuffs gaining importance in terms of ecological. Nowadays, alternative methods are needed in order to efficiently and economically remove the dyestuffs in large volume wastewater. In the study, the adsorption of Crystal Violet (CV) which is common in textile waste waters on the wheat bran was investigated. The different initial dye concentrations, $\mathrm{pH}$ values, adsorbent concentrations and temperature parameters were tested in order to determine the effects of adsorption on the $\mathrm{CV}$ dyestuff and optimum conditions were provided. The highest removal was obtained at the natural $\mathrm{pH}$ (6.24). As the amount of adsorbent increased up to certain value, the removal of dyestuff increased. Besides, it was observed that the adsorption reached a balance at 120 minutes and the removal efficiency decreased as the dyestuff concentration increased. However, increasing the temperature from $25^{\circ} \mathrm{C}$ to $45^{\circ} \mathrm{C}$ increased the removal of the dyestuff. The suitability of experimental data with Langmuir and Freundlich isotherms and pseudo-first and pseudo-second order kinetic models has been investigated. The parameters of these models and the thermodynamic parameters of the adsorption process were calculated. As part of characterization studies, the functional groups in the biosorption mechanism were examined and structural changes after biosorption were observed by Fourier Transform Infrared (FTIR) and Scanning Electron Microscopy (SEM) analyzes were performed for the wheat bran before and after the adsorption studies.
\end{abstract}

Keywords: Adsorption, Dye, Isotherm, Kinetics, Textile Waste Waters 


\section{Giriş}

Dünyadaki nüfus artışı ile beraber endüstrinin sürekli ve hızlı gelişmesi çevre kirliliği başta olmak üzere birçok sorunu da beraberinde getirmektedir. Günümüzde çevre kirliliğine sebep olan spesifik kirleticilerden biri de sentetik boyar maddelerdir. Boyar maddeler, başta tekstil sektörü olmak üzere çeşitli endüstri kuruluşlarında yaygın olarak kullanılmakta ve düşük miktarlarda kullanımı bile renkli atık su oluşturmaktadır (İmecik ve Diğrak, 2014). Tekstil ve boya üretim endüstrilerinden gelen atık sular, arıtılması zor olan atık su grubu arasinda yer almaktadır. Bunun sebebi boyaların genellikle sentetik kaynaklı ve kompleks aromatik moleküler yapıya sahip olmaları ve bu yapıların boyaları daha kararlı ve biyolojik parçalanmaya karşı dirençli hale getirmesidir. Dünya çapında yüz binin üzerinde sentetik boya ticari olarak kullanılmakta ve yıllık olarak yaklaşık yedi yüz bin ton üretim yapıldığ 1 tahmin edilmektedir. $\mathrm{Bu}$ boyaların yaklaşık \%1015 'inin endüstriyel atık sularla atıldığ 1 rapor edilmiștir. Düşük konsantrasyonlarda bile alıcı ortama deşarj edildiklerinde istenmeyen estetik problemlere yol açmaktadırlar (Deniz ve Şengül, 2015). Renk, alıcı ortamda 1 ş1k geçirgenliğini azaltarak fotosentetik aktiviteyi negatif olarak etkileyerek ortamdaki çözünmüş oksijen konsantrasyonunu azaltmaktadır. Endüstriyel atık sulardan renk gideriminde kullanılan geleneksel uygulamalar; iyon değişimi, adsorpsiyon, membran teknolojileri, filtrasyon, çöktürme, koagülasyon, oksidasyon olarak siralanabilir (Ziba vd., 2016). Bu yöntemler arasında yüksek verimlilik, tasarımın sadeliği, kullanım kolaylığı ve çeşitli boyalar için uygunluğu nedeniyle atık suların içerdiği tehlikeli inorganik / organik kirleticileri azaltmak için kullanılan ileri atık su arıtımının en etkin metotlarından biri adsorpsiyondur (Köklü and Ozer, 2018). Adsorpsiyon teknikleri konvansiyonel metotlar için fazla kararlı olan kirleticilerin giderimindeki verimlilikten dolayı son y1llarda ilgi görmektedir. Adsorpsiyon prosesi ekonomik bir yöntem olup, yüksek kalitede ürün oluşumu sağlar. Adsorpsiyon prosesi, boya/sorbent etkileşimi, adsorbanın yüzey alanı, tanecik büyüklüğü, sicaklık, $\mathrm{pH}$ ve temas süresi gibi pek çok fizikokimyasal faktörün etkisi altındadır. Adsorpsiyonla renk gideriminde en çok kullanılan adsorbent aktif karbondur. Ancak aktif karbon pahalı bir malzemedir. Adsorpsiyon tekniğinin etkinliğini belirleyen en önemli unsurlardan birinin kullanılan adsorbent olduğu bilinmektedir. Bu nedenle düşük maliyetli ve etkin adsorbenti belirleyebilmek amacıyla doğal malzemelerle çok sayıda çalışma yapılmıştır (Kocaer ve Alkan, 2002; Köklü and Ozer, 2018). Örneğin; kozalak (Dawood and Kanti Sen, 2012), ayçekirdeği kabuğu (Oguntimein, 2015), odun talaşı (Salazar-Rabago et al., 2017), kil (Bentahar et al., 2017) ile birlikte aktif karbon bazlı (Lawal et al., 2017) adsorbanlar da çeşitli boyar maddelerin giderimi için kullanılmıştır. Bu çalışmada, $\mathrm{CV}$ boyar maddesinin düşük maliyetli bir adsorbent olan buğday kepeği ile adsorpsiyon şartları başlangıç boyar madde konsantrasyonu, $\mathrm{pH}$, karıştırma süresi ve adsorbent dozuna bağlı olarak incelenmiş ve maksimum adsorpsiyon kapasitesi belirlenmiştir. Bunun yanında deneysel verilerin izoterm ve kinetik modellere uygunluğu araştırılmış ve bu modellere ait parametreler hesaplanmıştır. Ayrıca sıcaklık ve konsantrasyona bağlı olan termodinamik hesaplamalar yapılmıştır.

\section{Materyal ve Metot}

\subsection{Kullanilan Materyal ve Kimyasal Maddeler}

Adsorbent olarak kullanılan buğday kepeği, Erzincan ilindeki bir un fabrikasından temin edilerek $50{ }^{\circ} \mathrm{C}$ 'de 48 saat kurutulmuştur. Adsorbat olarak kullanılan reaktif tekstil boyar maddesi Crystal Violet (CV), Merck firmasından temin edilerek adsorpsiyon deneyleri gerçekleştirilmiştir. CV (katyonik boya) boyasının kimyasal formülü; 


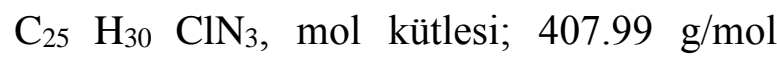
maksimum adsorpsiyonun gerçekleştiği dalga boyu $593 \mathrm{~nm}$ olup çözünebilen bir boyar maddedir. Boyar maddenin molekül yapısı Şekil 1'de görülmektedir..

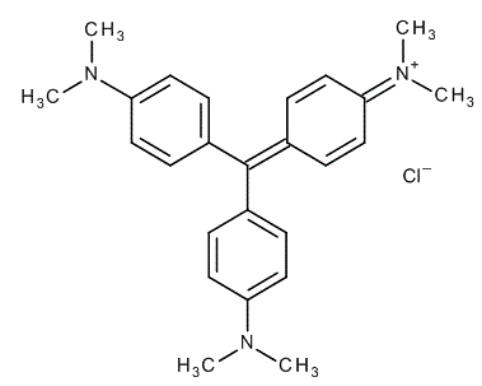

Şekil 1. Crystal Violet boyar maddesinin molekül yapis1.

\subsection{Deneysel Çalışma ve Analiz Yöntemi}

Adsorpsiyon çalışmaları, $200 \mathrm{ml}$ çalışma hacmindeki $250 \mathrm{ml}$ 'lik erlenlerde, sicaklık ve karıştırma hızı ayarlı Heidolph MR HeiStandard marka manyetik karıştırıcı kullanılarak yapılmıştır. Kesikli yapılan adsorpsiyon çalışmaları 150 rpm'de 120 dakikalık bir sürede gerçekleştirilmiştir. Adsorbentin boyar madde çözeltisine eklendiği an $\mathrm{t}=0$ anı olarak kabul edilmiş ve belirli aralıklarda örnekler alınmıştır. Alınan örnekler, Smart R17 marka santrifüjde 4000 rpm'de 20 dakika bekletildikten sonra, adsorplanmadan kalan boyar madde derişimi spektrofotometrik yöntem yardımıyla (593 $\mathrm{nm}$ dalga boyunda) tayin edilmiştir. Eşitlik 1 ve 2 kullanılarak sirası ile \% giderim ve adsorpsiyon kapasitesi $\mathrm{qe}_{\mathrm{e}}(\mathrm{mg} / \mathrm{g})$ değerleri hesaplanmıştır (Oguntimein, 2015).

$$
\begin{gathered}
\% \text { Giderim }=\frac{C_{0}-C_{e}}{C_{0}} 100 \\
q e=\frac{\left(C_{0}-C_{e}\right) V}{m}
\end{gathered}
$$

$\mathrm{C}_{0}$; başlangıçtaki boyar madde konsantrasyonu (mg/L), $\mathrm{C}_{\mathrm{e}}$; $\mathrm{t}$ anındaki boya konsantrasyonu (mg/L), V; çalışma hacmi (L), m; adsorbent miktarı (g).

\section{Bulgular ve Tartışma}

\subsection{Temas Süresinin Adsorpsiyon Üzerine} Etkisi

Atık su arıtım sistemleri için ekonomik açıdan etkili bir temas süresi çok önemlidir. $\mathrm{CV}$ boyar maddesinin temas süresini incelemek üzere 30 ve $50 \mathrm{mg} / \mathrm{L}$ boya konsantrasyonu farklı adsorbent miktarlarıyla denenmiştir. $\mathrm{Bu}$ denemeler sırasında farklı zamanlarda numuneler alınarak sistemin denge süresi gözlemlenmiştir. Şekil 2'den görüldüğü gibi 3 saatlik yapılan çalışmada adsorpsiyon ilk 30 dakikada hızlı bir şekilde ilerleyerek lineer bir artış göstermiştir. Bu süreden sonra giderim oldukça yavaş gerçekleşmiştir. 120 dakikadan sonra neredeyse giderim oranında değişiklik olmadığından temas süresi 120 dakika olarak alınmıştır. $\quad \mathrm{Bu}$ durum başlangıçta adsorpsiyon için kullanılan adsorbentin bağlandığı aktif bölgelerin çok olması ve aktif bölgelerin zamanla azalarak adsorpsiyon hızının yavaşlaması ile açıklanabilir (Wang et al., 2018). Yaklaşık \% 90 renk giderme veriminin elde edildiği 50 $\mathrm{mg} / \mathrm{L}$ boyar madde konsantrasyonu ve $3 \mathrm{~g} / \mathrm{L}$ adsorbent miktarı optimum değerler olarak seçilmiştir.

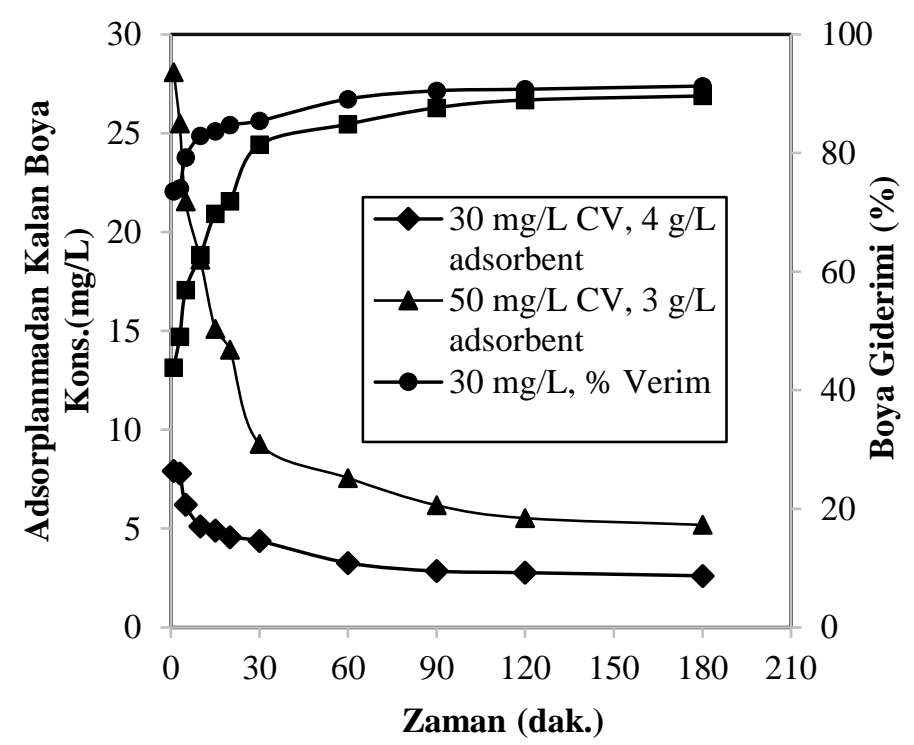

Şekil 2: Temas süresinin renk giderimine etkisi (Sıcaklık:25ㄷ, pH: doğal(6.24), Karıştırma hızı:150 rpm). 


\subsection{Adsorpsiyon Üzerine pH'nin Etkisi}

Ortam pH's1 adsorpsiyonu etkileyen en önemli parametrelerdendir. Çünkü adsorbentin yüzey yükü ve fonksiyonel grupların iyonizasyon derecesini etkileyebildiği gibi aynı zamanda adsorpsiyon mekanizmasinı da etkilemektedir (Elmoubarki et al., 2015). Buğday kepeği ile boyar madde giderimine ortam $\mathrm{pH}$ değerinin etkisi incelenirken; $\mathrm{pH}$ değeri 3.0, 4.0, 5.0, $6.24($ doğal $\mathrm{pH})$ ve 7.0 olarak değiştirilerek $(3 \mathrm{~g} / \mathrm{L}$ adsorbent miktarı, $50 \mathrm{mg} / \mathrm{L}$ boyar madde konsantrasyonu, oda sıcaklığı) denemeler yapılmıştır. Şekil 2'de de görüldüğü gibi en yüksek giderim doğal pH (6.24)'da yaklaşık \%90 olarak elde edilmiştir.

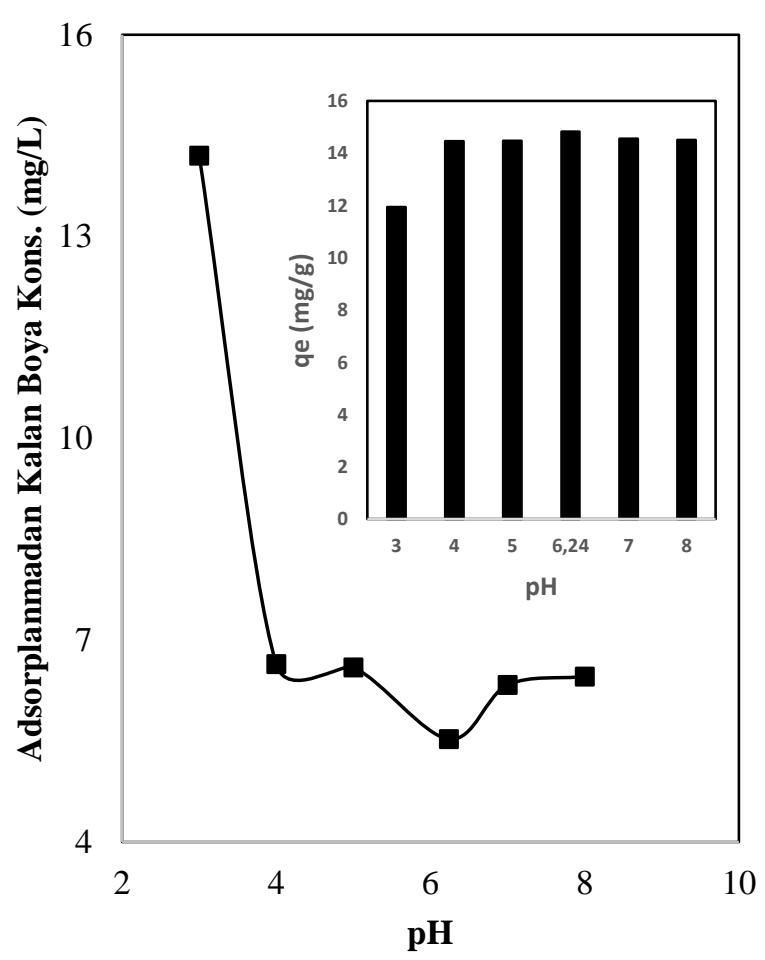

Şekil 3: Boyar madde giderimine başlangıç pH'sının etkisi (Boya konsantrasyonu:50 mg/L, Adsorbent miktarı: $3 \mathrm{~g} / \mathrm{L}$, Sıcaklık: $25^{\circ} \mathrm{C}$, Karıştırma hızı: 150 rpm).

Boya gideriminde genelde nötre yakın ve alkalin şartlar asidik şartlardan daha etkilidir. Çünkü $\mathrm{H}^{+}$, katyonik boyayı elektrostatik olarak çekebilen adsorbent üzerindeki negatif yüklerin miktarını azaltmaktadır (Liu et al., 2018).

\subsection{Adsorbent Miktarinin Adsorpsiyon Üzerine Etkisi}

Adsorbent dozu sabit bir boya konsantrasyonunda biyosorbentin sorpsiyon kapasitesini gösterdiğinden dolay1 adsorpisyonu etkileyen önemli bir faktör olarak dikkate alınmaktadır (Oguntimein, 2015). Adsorbent dozunun boyar madde giderimine etkisi araştırılırken, adsorbent konsantrasyonu $1.0,2.0,3.0,4.0$ ve $5.0 \mathrm{~g} / \mathrm{L}$ ' ye kadar değiştirilerek incelenmiştir. Deneyler $50 \mathrm{mg} / \mathrm{L}$ boyar madde konsantrasyonunda ve doğal $\mathrm{pH}$ 'da yapılmıştır. Şekil 4'te görüldüğü gibi, adsorbent miktarının artması boyar madde giderimini artırmıştır.

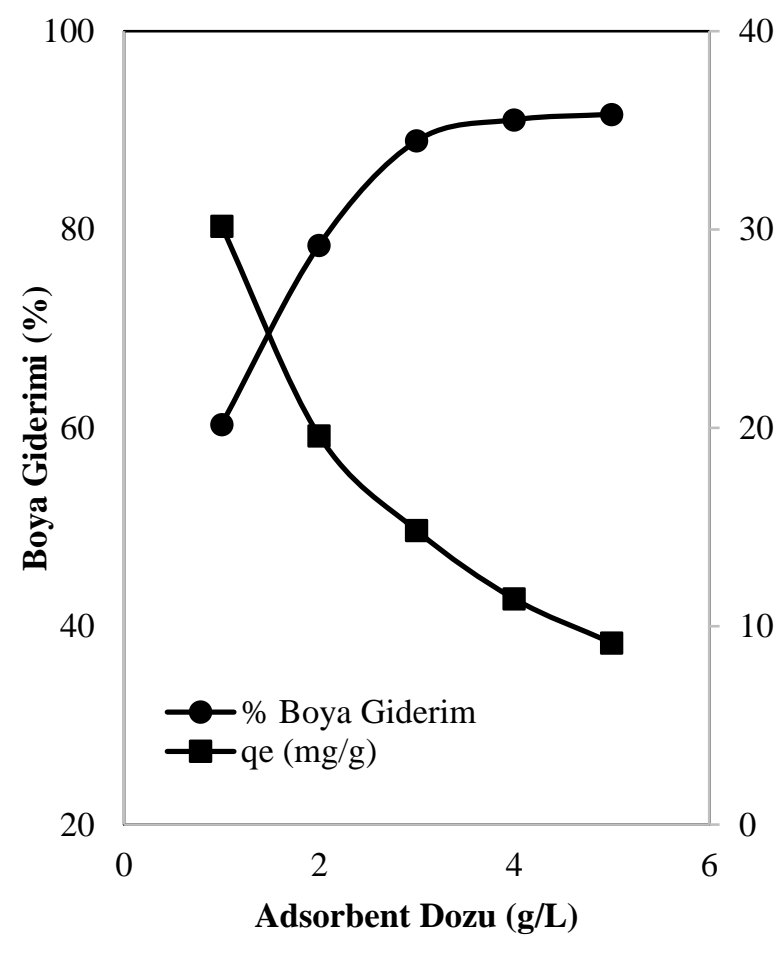

Şekil 4: Adsorbent miktarının adsorpsiyon üzerine etkisi (Boya konsantrasyonu:50 mg/L, pH: doğal pH (6.24), Sicaklık: $25^{\circ} \mathrm{C}$, Karıştırma hızı: $150 \mathrm{rpm}$ ).

$1.0 \mathrm{~g} / \mathrm{L}$ adsorbent ile $\mathrm{CV}$ boyar maddesi $\% 60$ civarında giderilirken $5.0 \mathrm{~g} / \mathrm{L}$ adsorbent ile $\% 92$ civarında giderilmektedir. Artan başlangıç biyosorbent konsantrasyonu ile \% giderim miktarı artarken birim adsorbent başına adsorplanan boyar madde miktarı $\mathrm{q}_{\mathrm{e}}$ $\mathrm{mg} / \mathrm{g}$ değeri azalmaktadır (Şekil 4). Biyosorbent konsantrasyonu ile giderim 
oranının artması adsorbent miktarındaki artışla birlikte adsorpsiyon için gerekli olan aktif bölgelerin sayısının artması ile açıklanırken, adsorpsiyon yoğunluğunun adsorbent konsantrasyonu ile birlikte azalmasi adsorpsiyon prosesi sirasinda doygunluğa ulaşamayan aktif bölgelerin miktarı ile açıklanabilir (Wang et al., 2018). $1.0 \mathrm{~g} / \mathrm{L}$ adsorbent kullanıldığında, adsorbentin gramı başına adsorplanan boya miktarı yaklaşık $30 \mathrm{mgboya} / \mathrm{g}$ iken adsorbent konsantrasyonu $5.0 \mathrm{~g} / \mathrm{L}$ olduğunda bu değer $9 \mathrm{mg}$ boya/g değerine düşmektedir. Adsorbentin miktarı arttıkça, mevcut adsorpsiyon bölgelerindeki artış, adsorpsiyon yüzdesinin yüksek olmasına neden olmuştur. Adsorbent yüzey üzerindeki aktif alanların sayısı dozaj arttırılarak yükseltilmiştir (Khamparia and Jaspal, 2016). Adsorbent miktarı arttıkça, adsorpsiyonun meydana gelebileceği bölgeler yani daha fazla bağlanma alanları ve dolayısıyla yüzey alanı da artmaktadır (Oguntimein, 2015).

\subsection{Boya Konsantrasyonunun Adsorpsiyon Üzerine Etkisi}

Buğday kepeği ile boyar madde giderimine başlangıç boyar madde konsantrasyonunun etkisi incelenirken; boyar madde konsantrasyonları 30, 40, 50, 60 ve $70 \mathrm{mg} / \mathrm{L}$ alınarak denemeler yapılmıştır. $30 \mathrm{mg} / \mathrm{L}$ boyar madde gideriminde verim yaklaşık olarak \%89 civarında iken $70 \mathrm{mg} / \mathrm{L}$ boyar madde \%83 verimle giderilmiştir. Deney sonuçları incelendiğinde boyar madde miktarının artması ile giderim verimi azalırken gram adsorbent başına adsorbe edilen boya miktarının arttığı gözlenmiştir. $30 \mathrm{mg} / \mathrm{L}$ boyar madde varlığında, adsorbentin gramı başına adsorplanan boya miktar1 $9 \mathrm{mg}$ boya/g ads. iken $70 \mathrm{mg} / \mathrm{L}$ boyar madde varlığında ise bu değer $19 \mathrm{mg}$ boya/g ads. değerine yükselmektedir.
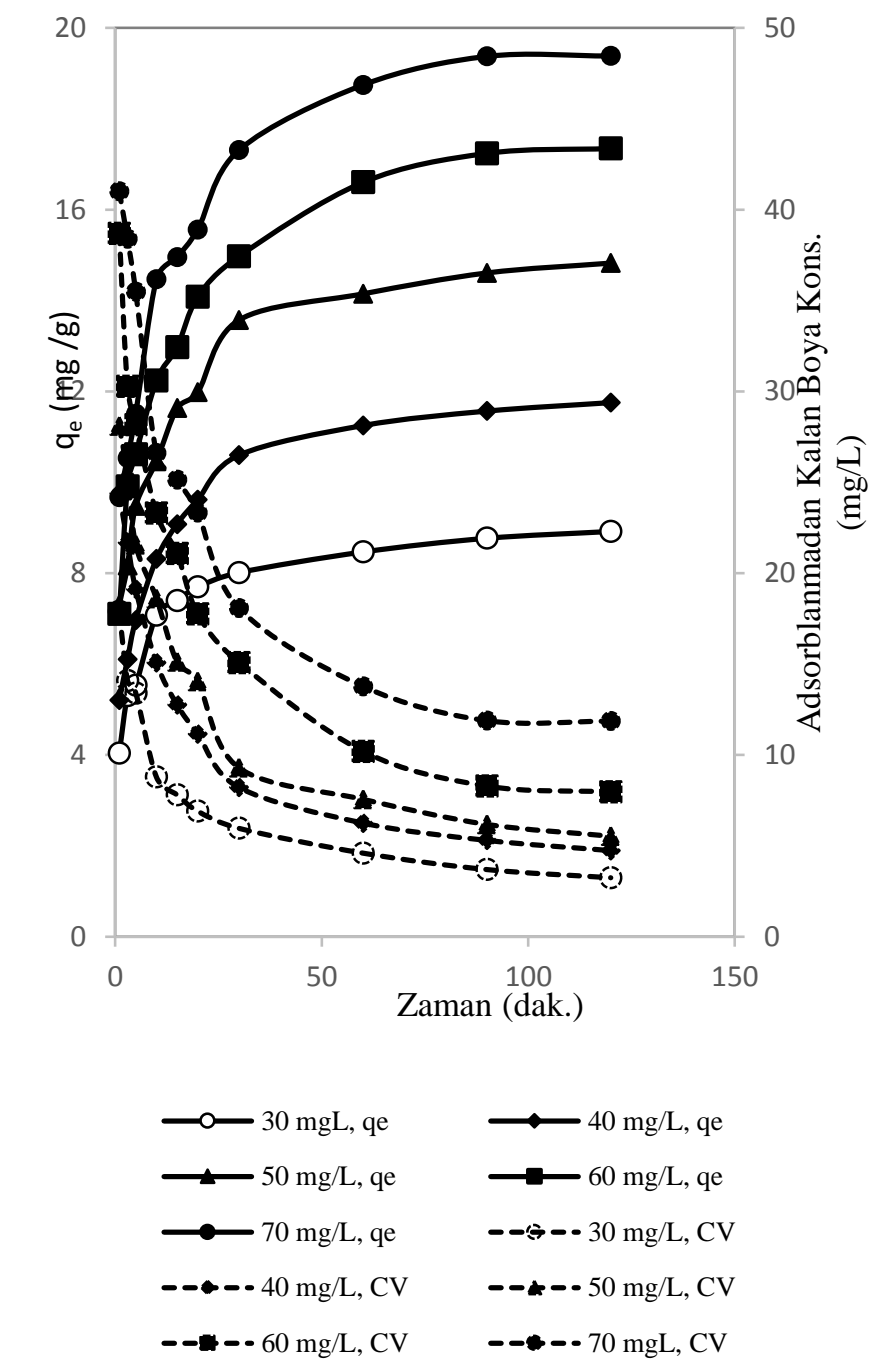

Şekil 5: Boya konsantrasyonunun adsorpsiyon üzerine etkisi (Adsorbent miktarı: $3 \mathrm{~g} / \mathrm{L}, \mathrm{pH}$ : doğal pH (6.24), Sıcaklık: $25^{\circ} \mathrm{C}$, Karıştırma hızı: $150 \mathrm{rpm}$ ).

Boyaların yüksek konsantrasyonlarda daha yüksek, düşük konsantrasyonlarda ise düşük adsorpsiyon kapasitesine sahip oldukları gözlemlenmiştir. Bunun nedeni, çözeltinin hacmi ile adsorbe edici yüzey arasında, adsorbatların sulu ve katı fazlar arasındaki kütle transfer direncinin üstesinden gelmek için itici güç olarak işlev gören bir konsantrasyon gradyanının olmasıdır. Ayrıca ortamdaki boya miktarındaki artışın adsorbent partikülleri ile çarpışma olasılığının artmasından da kaynaklanabileceği ifade edilmiştir (Lawal et al., 2017). Ancak adsorbent yüzeyindeki aktif bölgelerin zaman içerisinde doygunluğa ulaşması adsorpsiyonda azalmaya neden olabilmektedir. 


\subsection{Sicaklı̆̆ın Adsorpsiyon Üzerine Etkisi}

Adsorpsiyon kapasitesini ve moleküllerin difüzyon oranını etkileyerek adsorpsiyon dengesinin süresini değiştiren bir diğer faktör de sicaklıktır (Liu et al., 2018). Sicaklığın etkisi incelenirken $25{ }^{\circ} \mathrm{C}, 35^{\circ} \mathrm{C}$ ve $45{ }^{\circ} \mathrm{C}$ olmak üzere üç farklı sicaklık ve her üç sicakl1kta da 30, 40, 50, 60 ve $70 \mathrm{mg} / \mathrm{L}$ boyar madde konsantrasyonları denenmiştir. Elde edilen sonuçlar Şekil 5'te verilmiştir. Şekil 5 'ten de görüldüğg̈ gibi, sicaklığın $25^{\circ} \mathrm{C}$ 'den $45^{\circ} \mathrm{C}$ 'ye artırılması ile buğday kepeği ile boyar madde gideriminde adsorpsiyon veriminin bir miktar arttığı görülmüştür. $25^{\circ} \mathrm{C}$ 'de $70 \mathrm{mg} / \mathrm{L}$ boyar madde gideriminde; birim adsorbent başına adsorplanan boya miktarı yaklaşık $19 \mathrm{mg}$ boya/g ads. iken, $45^{\circ} \mathrm{C}$ 'de bu miktar artarak $20 \mathrm{mg}$ boya/g ads. değerine yükselmiştir. Aynı zamanda $25^{\circ} \mathrm{C}$ 'de $70 \mathrm{mg} / \mathrm{L}$ boyar madde $\% 83$ oranında giderilirken $45^{\circ} \mathrm{C}$ 'de ise $\% 86$ oranında giderilmiştir. Yaklaşık \%90 verimin elde edildiği $25{ }^{\circ} \mathrm{C}$, doğal $\mathrm{pH}$ (6.24), $50 \mathrm{mg} / \mathrm{L}$ boyar madde konsantrasyonu ve $3 \mathrm{~g} / \mathrm{L}$ adsorbent miktarı optimum değerler olarak kabul edilmiştir.

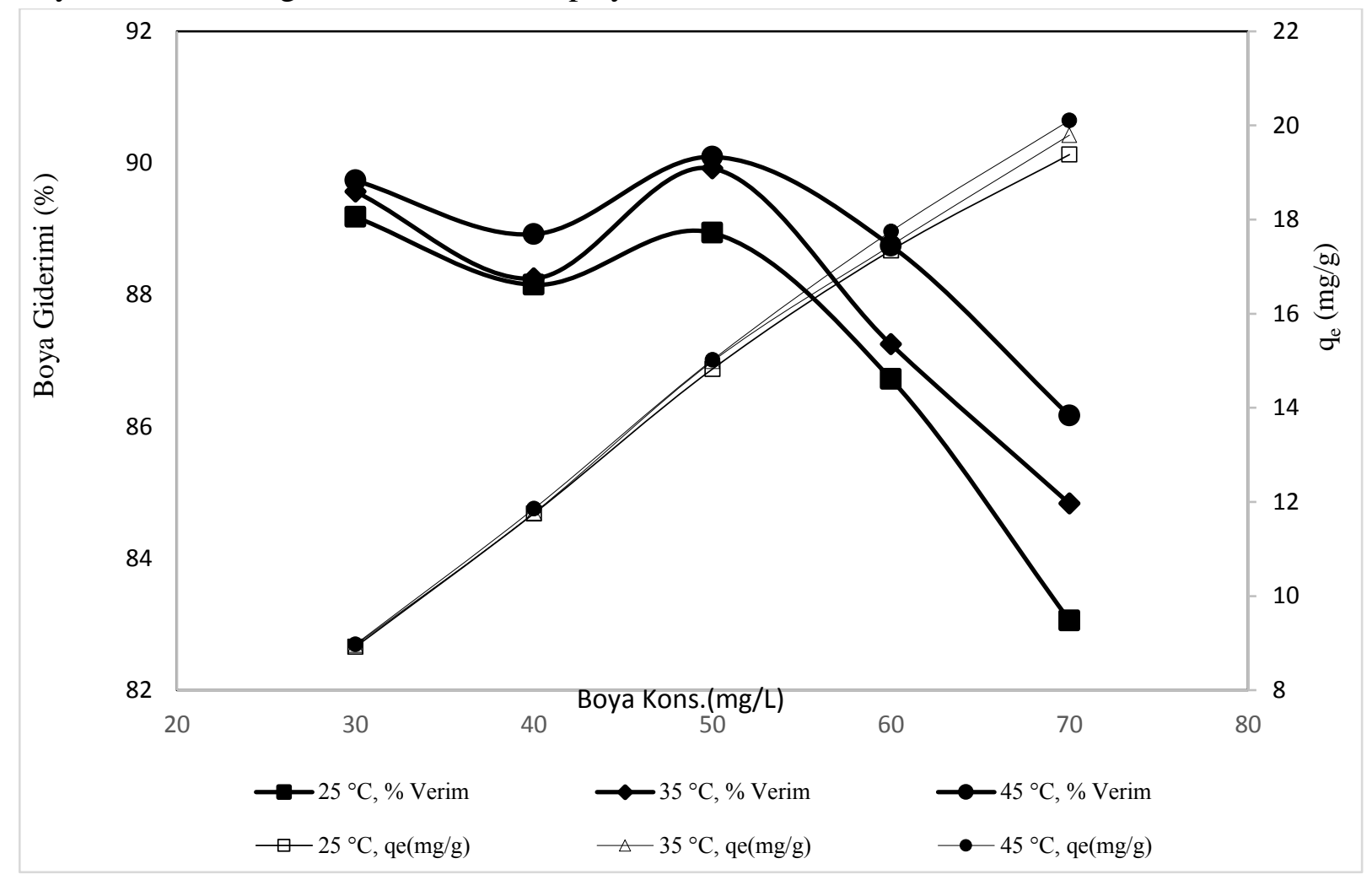

Şekil 6: Sıcaklığın adsorpsiyon üzerine etkisi (Adsorbent miktarı: 3 g/L, pH: doğal pH (6.24), Karıştırma hızı: $150 \mathrm{rpm})$.

Bunun nedeni, artan sicaklikla adsorbent üzerindeki bağlanma bölgelerinin sayısının artması ve daha çok bölgenin aktif hale gelmesidir. Sıcaklık artışı ile adsorpsiyon kapasitesinin artması endotermik bir mekanizmanın olduğunu göstermektedir (Yang and Hong, 2018).

\subsection{Adsorbent Karakterizasyonu}

\subsubsection{SEM Analizi}

Buğday kepeğine $\mathrm{CV}$ boyar maddesinin adsorpsiyonundan sonra yapisin gözlemlemek üzere taramalı elektron mikroskobu (SEM) ile görüntüsü alınmıştır (Şekil 7). Resimler, adsorpsiyondan sonra çok sayıda boya taneciğinin adsorbentin gözeneklerinin içinde beklendiği kadar derinde değil yüzeyinde biriktiğini göstermektedir. Adsorpsiyondan önce ve 
sonraki görüntülerden boyar maddenin görülmektedir.

buğday kepeği tanelerine bağlandığı açıkça
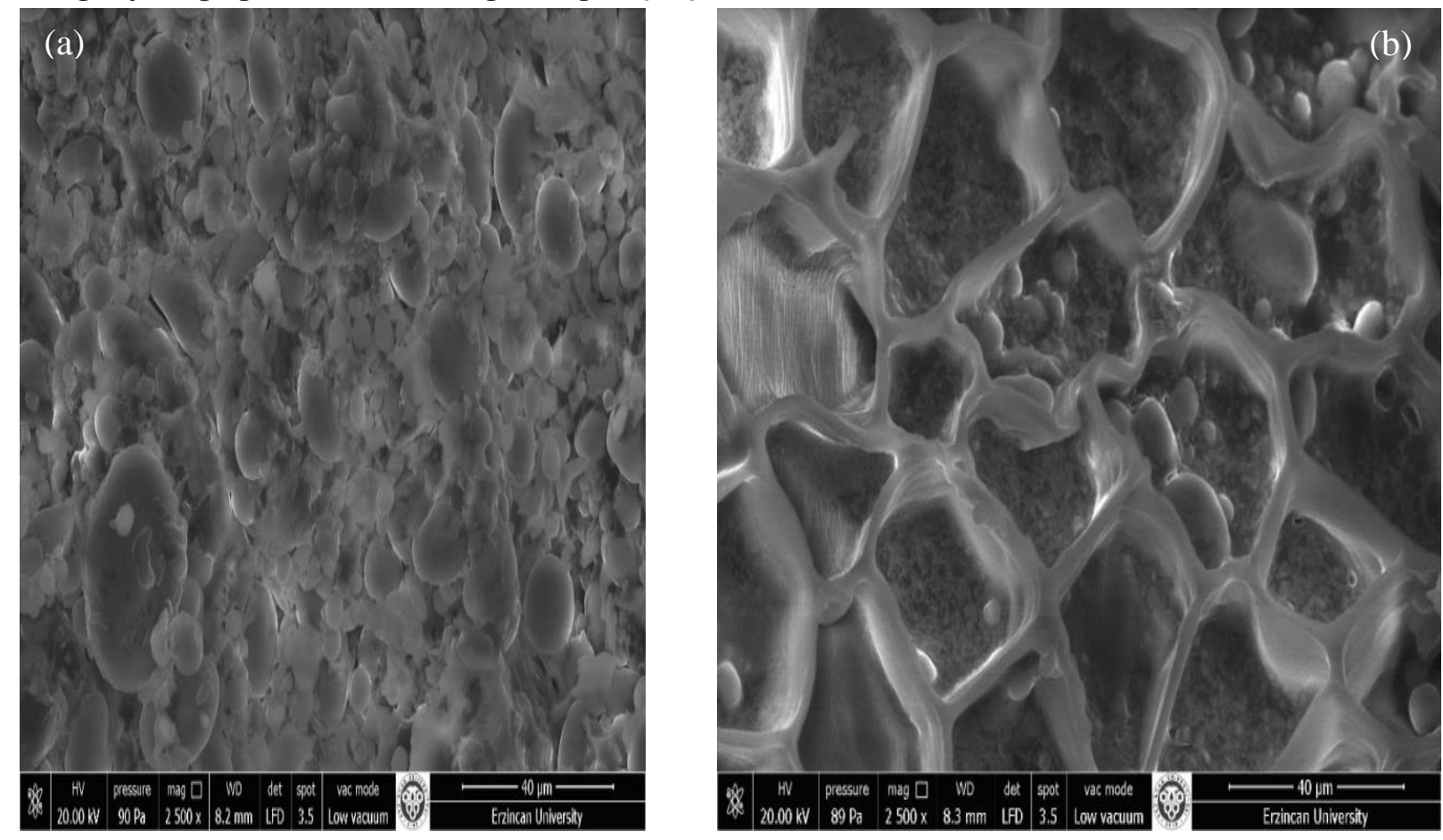

Şekil 7. Buğday kepeğinin boya adsorpsiyonundan önce (a) ve sonraki (b) SEM görüntüsü.

\subsubsection{FTIR Analizi}

Tablo 1. Buğday kepeğinin adsorpsiyon öncesi ve sonrası FTIR spektrum özellikler.

Adsorpsiyon bantları (1/cm)

Fonksiyonel gruplar Adsorpsiyondan önce Adsorpsiyondan sonra

\begin{tabular}{ccc}
\hline 3272 & 3302 & OH veya N-H \\
\hline 2923 & 2922 & $\mathrm{C}-\mathrm{H}$ \\
\hline 1746 & 1737 & $\mathrm{C}-\mathrm{H}$ veya $\mathrm{C}=\mathrm{O}$ \\
\hline 1646 & 1647 & $\mathrm{C}=\mathrm{O}$ veya $\mathrm{C}=\mathrm{C}$ \\
\hline 1338 & 1240 & $\mathrm{C}-\mathrm{N}$ veya C=O \\
\hline 706 & 722 & $\mathrm{C}-\mathrm{N}$ veya C-H \\
\hline 526 & 522 & $\mathrm{C}-\mathrm{H}$ \\
\hline 446 & 441 & Amin gruplar1
\end{tabular}

FTIR adsorbentin fonksiyonel gruplar1 (Perkin-Elmer) ile 400-4000 1/cm arasinda hakkında bilgi sahibi olmak ve kimyasal analiz yapılmıştır. CV adsorpsiyonundan yapısını anlamak için CV'in buğday kepeği önce ve sonra FTIR sonuçları Şekil 8, a ve üzerine adsorpsiyonunda, adsorpsiyondan b'de gösterilmiştir. Bu sonuçlara karşılık önce ve sonrasinda Fourier Transform gelen adsorpsiyon öncesi ve sonrası oluşan Infrared Spectrometer (FTIR GX 2000, bant aralıkları Tablo 1'de verilmiştir. 
(a)

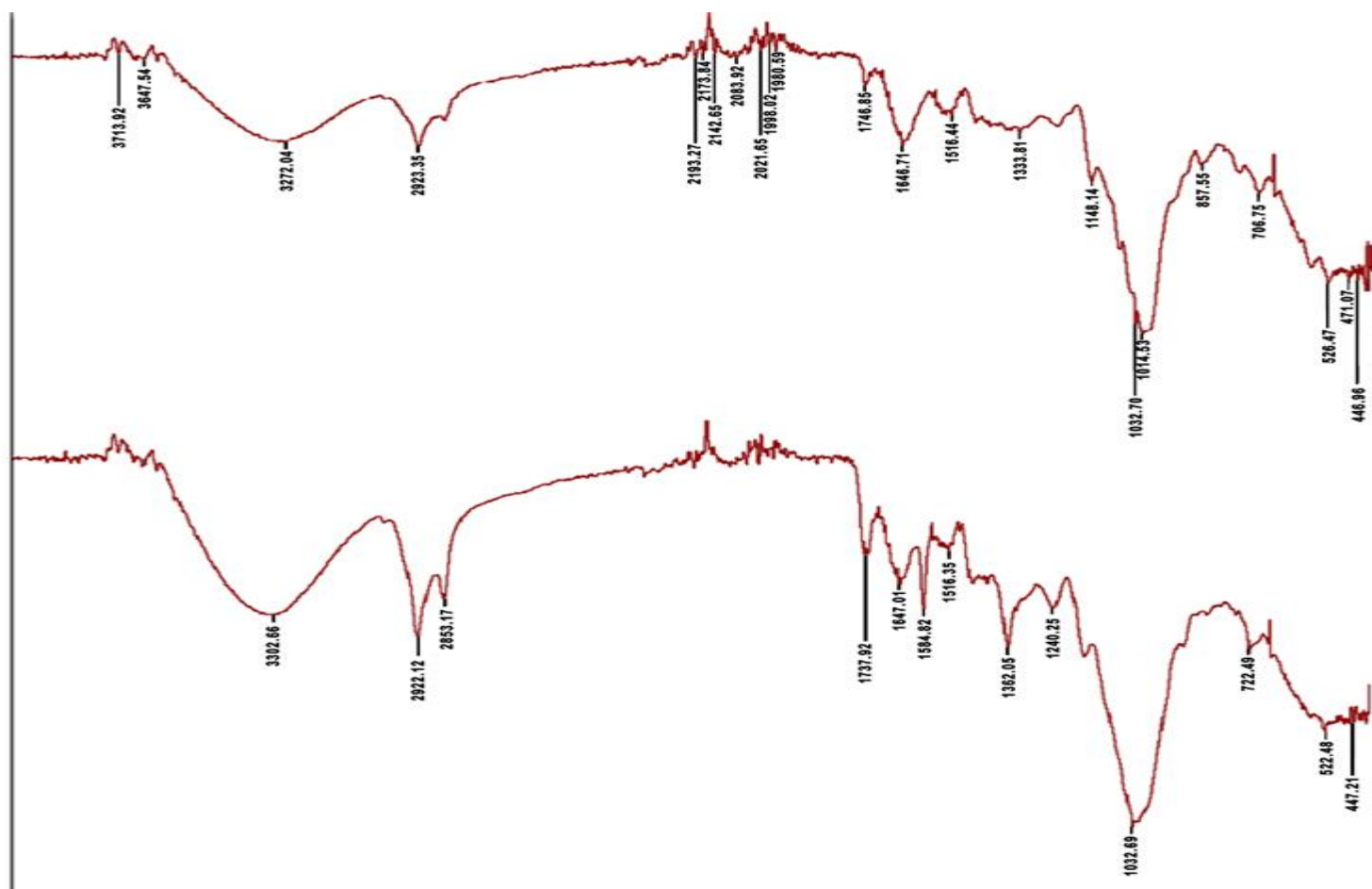

Şekil 8. Buğday kepeği ile CV adsorpsiyonunun FTIR analizi: (a) adsorpsiyondan önce (b) adsorpsiyondan sonra.

\subsection{Adsorpsiyon Eşitlikleri}

Adsorpsiyon izoterm modelleri, adsorpsiyon işleminin uygulanabilirliğini değerlendirmek için kullanılan temel fizikokimyasal verileri sağlar. Her bir izoterm modeli, adsorbent yüzey özellikleri, boya moleküllerine karşı adsorbent afiniteleri, mekanizmaları ve biyosorbentin alım kapasitesi hakkında önemli bilgiler sağlayan belirli sabitlerle karakterize edilir (Rangabhashiyam et al., 2017). Bu çalışmada CV ve buğday kepeği arasındaki etkileşimin doğasını anlamak için Langmuir (Eşitlik 3) ve Freundlich (Eşitlik 4) (Omer et al., 2017) izoterm modelleri kullanılmıştır.

$\frac{c_{e}}{q_{e}}=\frac{C_{e}}{Q_{0}}+\frac{1}{k_{L^{*} Q_{0}}}$

$L n q_{e}=\frac{1}{n} \operatorname{Ln} C_{e}+\operatorname{Ln} k_{f}(4)$

Eşitlik 3'de $C_{\mathrm{e}}(\mathrm{mg} / \mathrm{L})$; kalan boya denge konsantrasyonu, $\quad \mathrm{q}_{\mathrm{e}}(\mathrm{mg} / \mathrm{g}) ; \quad$ adsorpsiyon kapasitesi, $\mathrm{Q}_{0}(\mathrm{mg} / \mathrm{g})$ ve $\mathrm{k}_{\mathrm{L}}(\mathrm{L} / \mathrm{g})$ siras1 ile maksimum adsorpsiyon kapasitesi ve adsorpsiyon oranı ile ilgili Langmuir sabitleridir. Eşitlik 4'de $\mathrm{k}_{\mathrm{f}}(\mathrm{L} / \mathrm{g})$; adsorpsiyon kapasitesi, n; adsorpsiyon yoğunluğu ile ilgili Freundlich sabitleridir. Freundlich sabitleri, adsorpsiyon kapasitesi ve adsorpsiyon yoğunluğuna bağlanırken, Langmuir sabitleri, maksimum adsorpsiyon kapasitesi ve adsorpsiyonun bağlanma enerjisi ile ilişkilidir. (Mustafa et al., 2017). Adsorpsiyon izotermleri için yapılan çalışmalarda, başlangıç boya konsantrasyonlar1 30-70 mg/L, adsorbent konsantrasyonu $3 \mathrm{~g} / \mathrm{L}$ 'de sabit tutulurken, sıcaklıklar 25,35 ve $45^{\circ} \mathrm{C}$ olarak seçilmiştir. Uygulanan Langmuir ve Freundlich İzoterm eğrileri Şekil 9'da verilmiştir. İzotermlerin deneysel verilere uygunluğu araştırılarak elde edilen regresyon katsayıları ve izoterm sabitleri Tablo 2'de gösterilmiştir. 

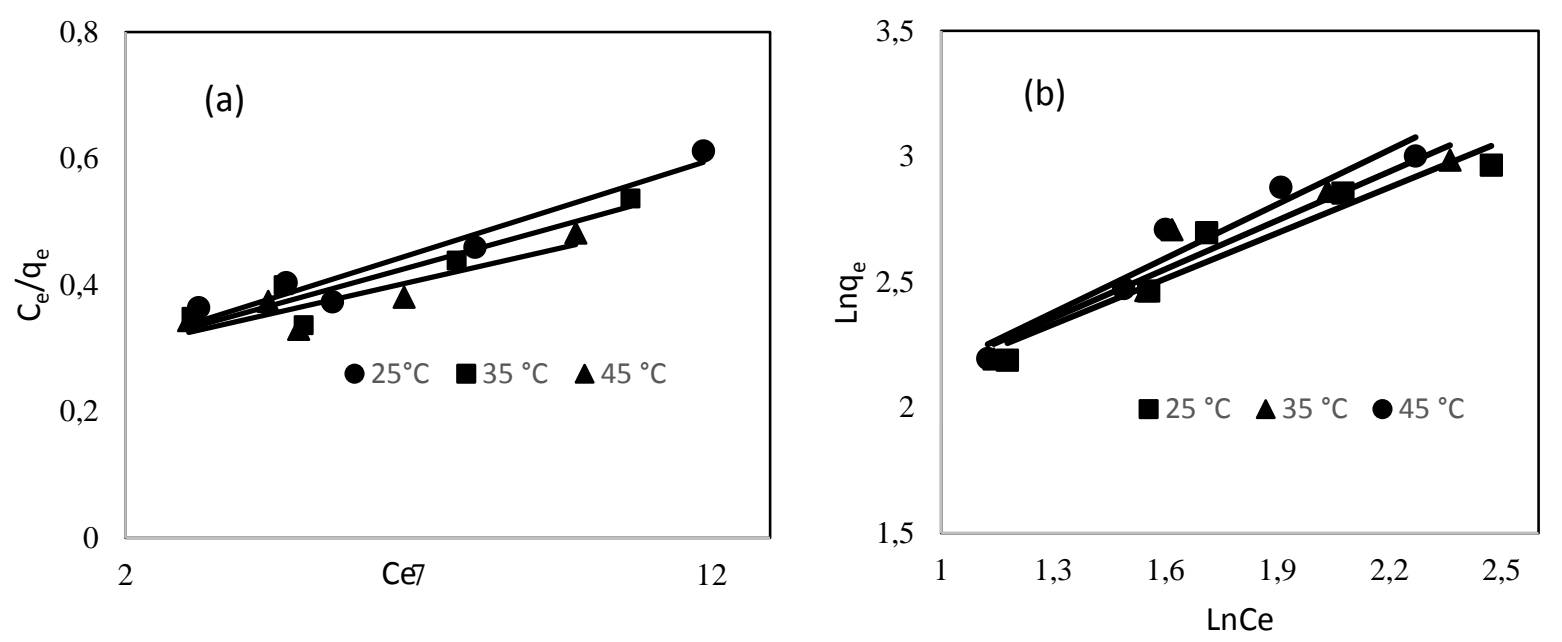

Şekil 9. CV boyar maddesinin farklı sicaklıklarda buğday kepeğine adsorpsiyonunda (a) Langmuir, (b) Freundlich izotermleri.

Langmuir modeli, adsorpsiyonun homojen tek tabaka yüzey üzerinde oluştuğu ve yüzeyde bulunan bölgelerin enerjisel olarak eşdeğer olduğu esasına dayanmaktadır. Freundlich modeli ise adsorpsiyonun heterojen yüzey üzerinde oluştuğu ve yüzey üzerindeki enerji dağılımının eşit olmadığı esasına dayanmaktadır (Da Fontoura et al., 2017). Regresyon katsayıları $\mathrm{R}^{2}$ değerlerinden, CV'in adsorpsiyonda deneysel verilerin Freundlich İzoterm modeline daha iyi uyduğu gözlemlenmiştir. Freundlich izoterm modeli, çok katmanlı biyosorpsiyonu ifade etmektedir (Rangabhashiyam et al., 2017). Freundlich izoterminden elde edilen $1 / \mathrm{n}$ değerlerinin düşük (sıfıra yakın) olması buğday kepeği yüzeyinin daha heterojen olduğunun göstergesidir (Albadarin et al., 2017).

Tablo 2. Farklı sıcaklıklarda buğday kepeği ile CV adsorpsiyonunda izoterm sabitleri.

\begin{tabular}{llll}
\hline İzoterm & $25^{\circ} \mathrm{C}$ & $35^{\circ} \mathrm{C}$ & $45^{\circ} \mathrm{C}$ \\
\hline Langmuir & & & \\
\hline $\mathrm{Q}_{\mathrm{o}}(\mathrm{mg} / \mathrm{g})$ & 34.246 & 39.062 & 47.619 \\
\hline $\mathrm{k}_{\mathrm{L}}(\mathrm{L} / \mathrm{g})$ & 0.120 & 0.101 & 0.080 \\
\hline $\mathrm{R}^{2}$ & 0.932 & 0.8735 & \\
\hline Freundlich & & & 4.234 \\
\hline $\mathrm{k}_{\mathrm{F}}(\mathrm{L} / \mathrm{g})$ & 4.682 & 4.548 & 1.390 \\
\hline $\mathrm{n}$ & 1.650 & 1.544 & 0.9341 \\
\hline $\mathrm{R}^{2}$ & 0.929 & 0.9213 & \\
\hline
\end{tabular}

\subsection{Adsorpsiyon Kinetiği}

$\mathrm{CV}$ boyar maddesinin adsorpsiyon kinetiğini analiz etmek için yalancı birinci ve yalancı ikinci dereceden kinetik modelleri partiküller arası difüzyonu araştırmak üzere deneysel verilere uygulanmıştır. Eşitliklerden elde edilen sabitler Tablo 3'te verilmiştir. Yalancı birinci dereceden kinetik eşitliğinin lineer hali Eşitlik 6'da verilmiştir.

$$
\log \left(q_{e}-q_{t}\right)=\log q_{e}-\frac{k_{1}}{2,303} t
$$

Eșitlik 6'da qe (mg/g); eșitlikte gram başına adsorplanan boyar madde miktarı, $\mathrm{q}_{\mathrm{t}}(\mathrm{mg} / \mathrm{g})$; $\mathrm{t}$ anında gram başına adsorplanan boyar madde miktarı, t'ye karşı çizilen $\log \left(\mathrm{q}_{\mathrm{e}}-\mathrm{q}_{\mathrm{t}}\right)$ (Şekil 10) grafiğinden elde edilen eğim ve kesim noktasindan hesaplanan $\mathrm{k}_{1}$ (1/ min); birinci derece hız sabiti, q e (mg/g); eşitlikteki adsorpsiyon kapasitesidir. Yalancı ikinci dereceden kinetik eşitliğinin lineer hali Eşitlik 7'de verilmiştir.

$\frac{t}{q_{t}}=\frac{1}{k_{2} q_{e}^{2}}+\frac{1}{q_{e}} t$ 
Eşitlik 7'den t'ye karşı çizilen t/q $\mathrm{q}_{\mathrm{t}}$ grafiğinden (Şekil 11) elde edilen eğim ve kesim noktaları ile hesaplanan $\mathrm{q}_{\mathrm{e}}(\mathrm{mg} / \mathrm{g})$; eşitlikteki adsorpsiyon kapasitesi, $\mathrm{q}_{\mathrm{t}}(\mathrm{mg} / \mathrm{g}) ; \mathrm{t}$ anındaki adsorpsiyon kapasitesi, $\mathrm{k}_{2}(1 / \mathrm{min})$; ikinci derece hız sabiti.
Eşitlik 8'de $\mathrm{k}_{2}$; yalancı ikinci derece hız sabiti, qe; yalancı ikinci derece kinetikle hesaplanan adsorpsiyon kapasitesi, h;adsorpsiyon oranı. (Ceylan et al., 2017).

$$
h=k_{2} q_{e}^{2}
$$

Tablo 3.Farklı başlangıç CV konsantrasyonlarında ve farklı sıcaklıklarda CV boyar maddesinin buğday kepeği ile adsorpsiyonunda kinetik parametreler.

\begin{tabular}{|c|c|c|c|c|c|c|c|c|}
\hline \multirow{2}{*}{$\begin{array}{c}\text { CV } \\
\text { kons. } \\
(\mathrm{mg} / \mathrm{L})\end{array}$} & \multicolumn{4}{|c|}{ Yalancı 1. Derece Kinetik } & \multicolumn{3}{|c|}{ Yalancı 2. Derece Kinetik } & \multirow[b]{2}{*}{ h (mg/gdak } \\
\hline & $\begin{array}{c}\text { qe(deneyse } \\
\text { l) } \\
(\mathrm{mg} / \mathrm{g})\end{array}$ & $\begin{array}{c}\text { qe(kineti } \\
\text { k) } \\
(\mathrm{mg} / \mathrm{g})\end{array}$ & $\begin{array}{c}\mathbf{k}_{1}(\mathrm{~L} / \mathrm{dak} \\
)\end{array}$ & $\mathbf{R}^{2}$ & $\begin{array}{c}\text { qe(kinetik) } \\
(\mathrm{mg} / \mathrm{g})\end{array}$ & $k_{2}$ (g/mgdak) & $\mathbf{R}^{2}$ & \\
\hline \multicolumn{9}{|l|}{$25^{\circ} \mathrm{C}$} \\
\hline 30 & 8.918 & 3.344 & 0.0356 & 0.9451 & 9.057 & 0.0378 & 0.9995 & 3.100 \\
\hline 40 & 11.753 & 5.353 & 0.0391 & 0.9751 & 12.048 & 0.0221 & 0.9993 & 3.207 \\
\hline 50 & 14.823 & 6.354 & 0.0386 & 0.9720 & 15.151 & 0.0189 & 0.9991 & 4.338 \\
\hline 60 & 17.344 & 9.134 & 0.0472 & 0.9875 & 17.857 & 0.0140 & 0.9988 & 6.026 \\
\hline 70 & 19.680 & 9.044 & 0.0382 & 0.9889 & 20.161 & 0.0127 & 0.9988 & 5.162 \\
\hline \multicolumn{9}{|l|}{$35^{\circ} \mathrm{C}$} \\
\hline 30 & 8.956 & 2.851 & 0.0382 & 0.9454 & 9.074 & 0.0486 & 0.9998 & 4.001 \\
\hline 40 & 11.766 & 4.221 & 0.0444 & 0.9616 & 11.961 & 0.0345 & 0.9997 & 4.935 \\
\hline 50 & 14.986 & 6.354 & 0.0432 & 0.9882 & 15.290 & 0.0209 & 0.9992 & 4.886 \\
\hline 60 & 17.449 & 7.151 & 0.0469 & 0.9918 & 17.825 & 0.0195 & 0.9994 & 6.195 \\
\hline 70 & 19.794 & 6.412 & 0.0356 & 0.8403 & 20.080 & 0.0198 & 0.9995 & 7.983 \\
\hline \multicolumn{9}{|l|}{$45^{\circ} \mathrm{C}$} \\
\hline 30 & 8.973 & 2.722 & 0.0467 & 0.9597 & 9.132 & 0.0575 & 0.9999 & 4.795 \\
\hline 40 & 11.856 & 4.273 & 0.0481 & 0.9721 & 12.062 & 0.0359 & 0.9998 & 5.223 \\
\hline 50 & 15.015 & 5.878 & 0.0538 & 0.9478 & 15.267 & 0.0288 & 0.9998 & 6.712 \\
\hline 60 & 17.479 & 6.420 & 0.0354 & 0.9536 & 18.018 & 0.0196 & 0.9994 & 6.363 \\
\hline 70 & 20.105 & 6.070 & 0.0525 & 0.961 & 20.366 & 0.0289 & 0.9999 & 11.986 \\
\hline
\end{tabular}

Tablo 3'ten görüldüğü gibi yalancı birinci dereceden eşitlikte hesaplanan $\mathrm{R}^{2}$ değerleri düşük ve eşitlikte hesaplanan adsorpsiyon kapasiteleri ( $\left.\mathrm{q}_{\mathrm{e}, \text { deneysel }}\right)$, ile kinetikle hesaplanan $\left(\mathrm{q}_{\mathrm{e}, \mathrm{kinetik}}\right)$ adsorpsiyon kapasiteleri birbirleriyle uyuşmamaktadır. $\mathrm{Bu}$ durum $\mathrm{CV}$ boyar maddesinin buğday kepeği ile adsorpsiyonunda birinci derece eşitliğe uymadığını göstermektedir. İkinci derece kinetik modeli için hesaplanan $\mathrm{q}_{\mathrm{e}, \text { kinetik }}$ değerleri ile $\mathrm{q}_{\mathrm{e}, \mathrm{deneysel}}$ değerleri birbirlerine çok yakın bulunmuştur (Tablo 3). $\mathrm{R}^{2}$ değerleri birinci derece kinetiğe göre daha yüksek hesaplanmıştır $\left(R^{2}=0.99\right)$. Aynı zamanda $\mathrm{CV}$ adsorpsiyonunda ikinci derece hız sabiti $\left(k_{2}\right)$ sıcaklık artışı ile artış göstermiştir. $\mathrm{k}_{2}$ değerleri çözelti sıcaklığı $25^{\circ} \mathrm{C}^{\prime} \mathrm{den} 45^{\circ} \mathrm{C}^{\prime}$ ye çıkması ile $50 \mathrm{mg} / \mathrm{L} \mathrm{CV}$ konsantrasyonu için 0.0189 'dan 0.0288 (g/mgdak)'a yükselmiştir (Tablo 3) (Akar et al., 2008). Yalanci ikinci derece kinetik modeli, adsorbent ve çözelti arasındaki elektronların paylaşımı veya değişimi yoluyla değerlik kuvvetlerini içeren kimyasal bir sorpsiyon olabileceği varsayımına dayanmaktadır (Ertugay, 2016). Başlangıç adsorpsiyon oranlarını ifade eden $h$ değerleri de boya konsantrasyonunun artması ile artış göstermiştir (Tablo 3). 

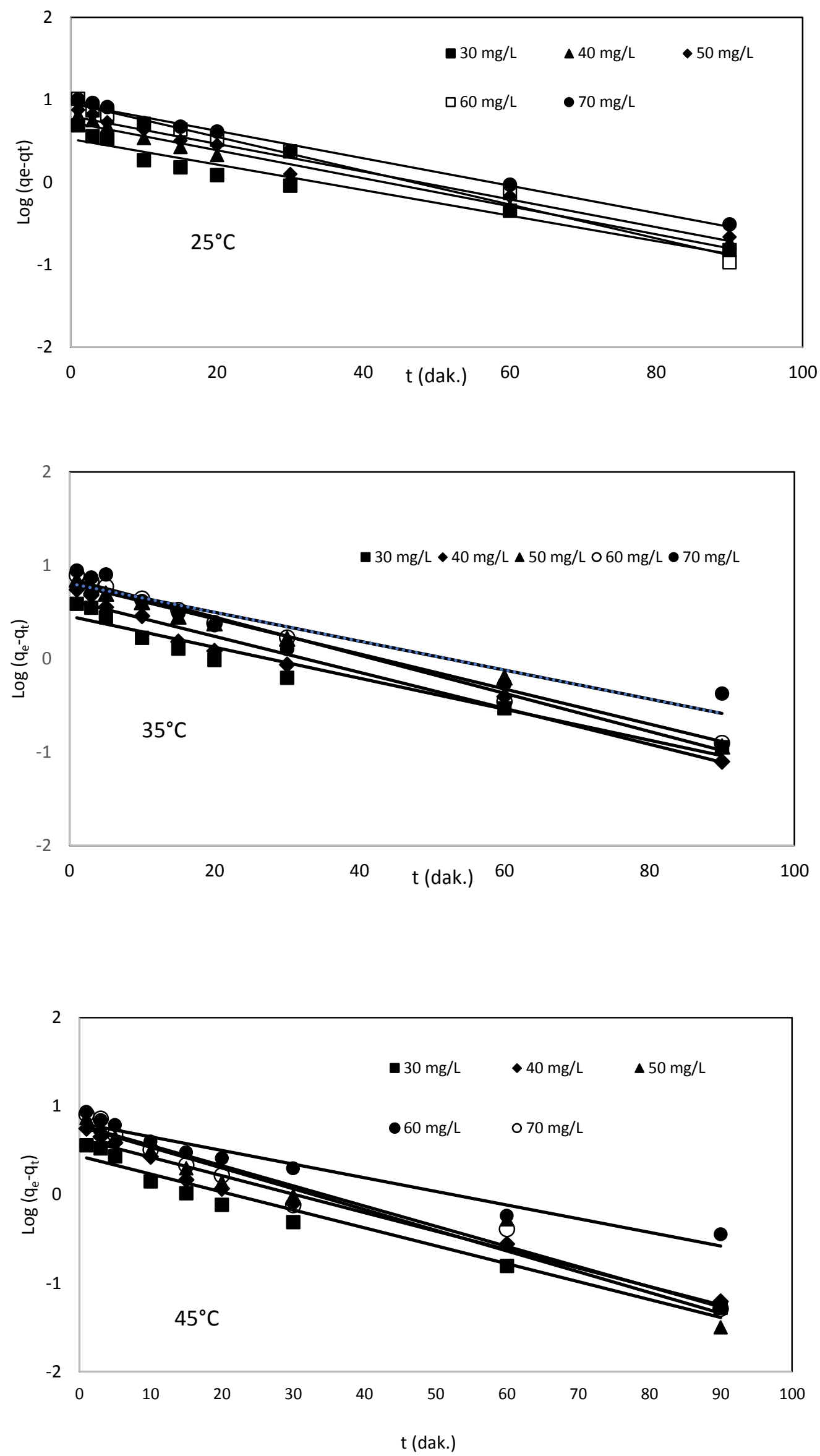

Şekil 10. Farklı başlangıç konsantrasyonlarında ve sıcaklıklarda CV boyar maddesinin buğday kepeği ile adsorpsiyonu için yalancı birinci derece kinetik model. 

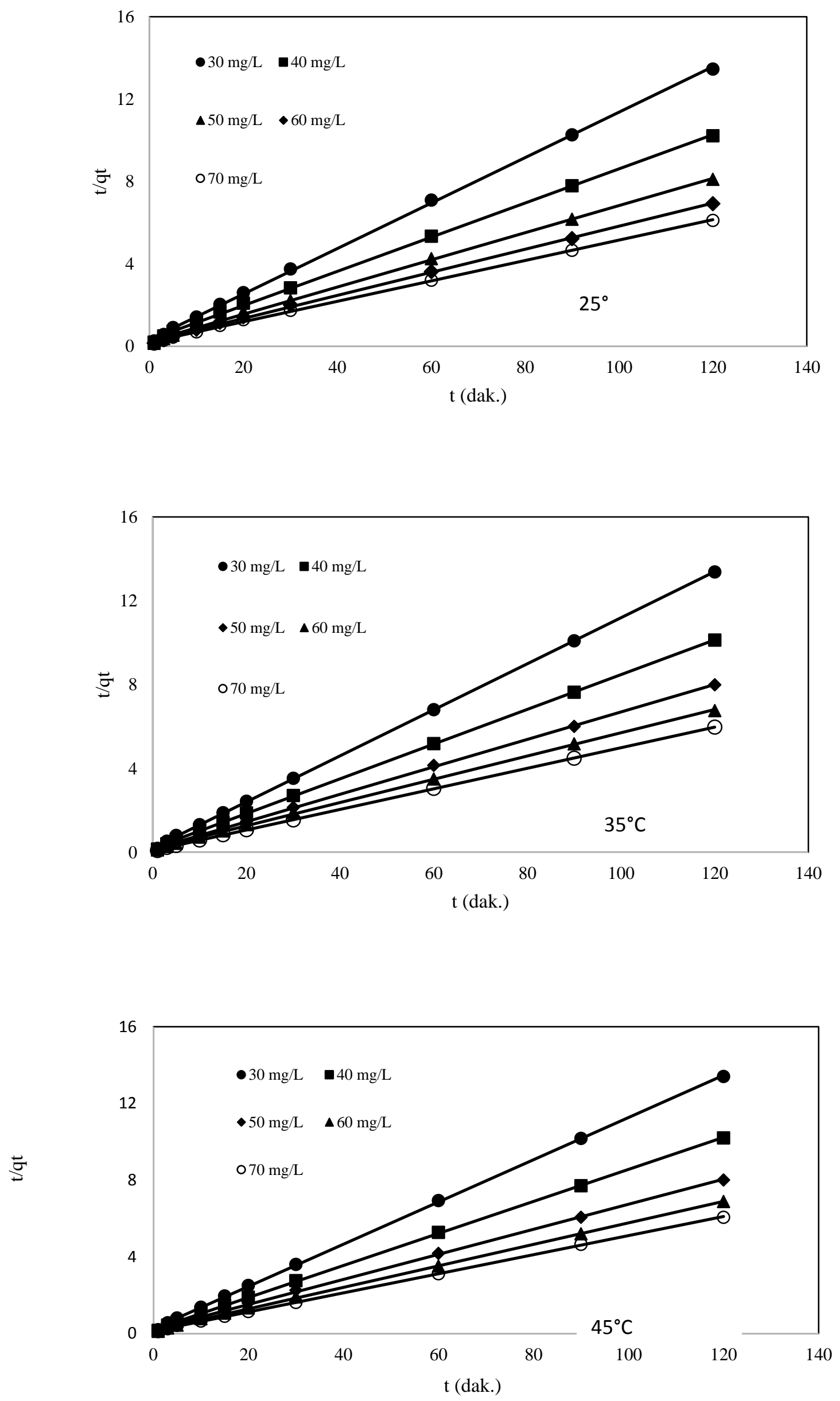

Şekil 11. Farklı başlangıç konsantrasyonlarında ve sıcaklıklarda CV boyar maddesinin buğday kepeği ile adsorpsiyonu için yalancı ikinci derece kinetik model. 
Tablo 3’ten görüldüğü gibi, bütün sıcaklıklarda konsantrasyon artışı ile ikinci derece hız sabitlerinde düşüş gözlemlenmiş, sıcaklık artışı ile bu değer yükselmiştir. Kinetik sabitler, genellikle konsantrasyondaki artışla azalma eğilimlidir. Bununla birlikte, CV moleküllerinin içindeki aktif bölgeleri değerlendirmek için alan sınırlamalarını ele alırsak daha yüksek konsantrasyonlarda, daha yüksek bir direncin olması beklenir ve daha düşük kinetik sabitler elde edilir (Santos and Boaventura, 2016).

\subsection{Aktivasyon Enerjisi ve Termodinamik}

\section{Parametreler}

Buğday kepeği ile CV boyar maddesinin adsorpsiyon çalışmasında Aktivasyon enerjisi Eşitlik 9 'da verilen Arrhenius eşitliği ile hesaplanmıştır (Mondal et al., 2017).

$L n k_{2}=\operatorname{Ln} A-\frac{E_{a}}{R T}$

Eşitlik 9'da $E_{a}$; aktivasyon enerjisi $(\mathrm{kj} / \mathrm{mol})$, $A$; Arrhenius faktörü, $R$; gaz sabiti (8.314 $\mathrm{J} / \mathrm{mol} \mathrm{K})$ ve $T$; sicaklık $(K)$. $1 / T$ 'ye karşılık çizilen $\mathrm{Lnk}_{2}$ grafiğinin eğim ve kesim noktalarından $E_{a}$ ve $A$ değerleri hesaplanmıştır (Şekil 12). Genellikle düşük aktivasyon enerjileri $(5-40 \mathrm{~kJ} / \mathrm{mol})$ fiziksel adsorpsiyon olarak, yüksek aktivasyon enerjileri ise (40-800 kJ/ mol) kimyasal adsorpsiyon olarak karakterize edilir (Tang et al., 2012). Buğday kepeği ile CV boyar maddesinin adsorpsiyonunda farklı konsantrasyonlardaki aktivasyon enerjileri 13,38-32,40 kj/mol arasında hesaplanmıştır. $\mathrm{Bu}$ sonuçlar çalışmanın fiziksel bir adsorpsiyon olduğunu gösterdiği düşünülmektedir.

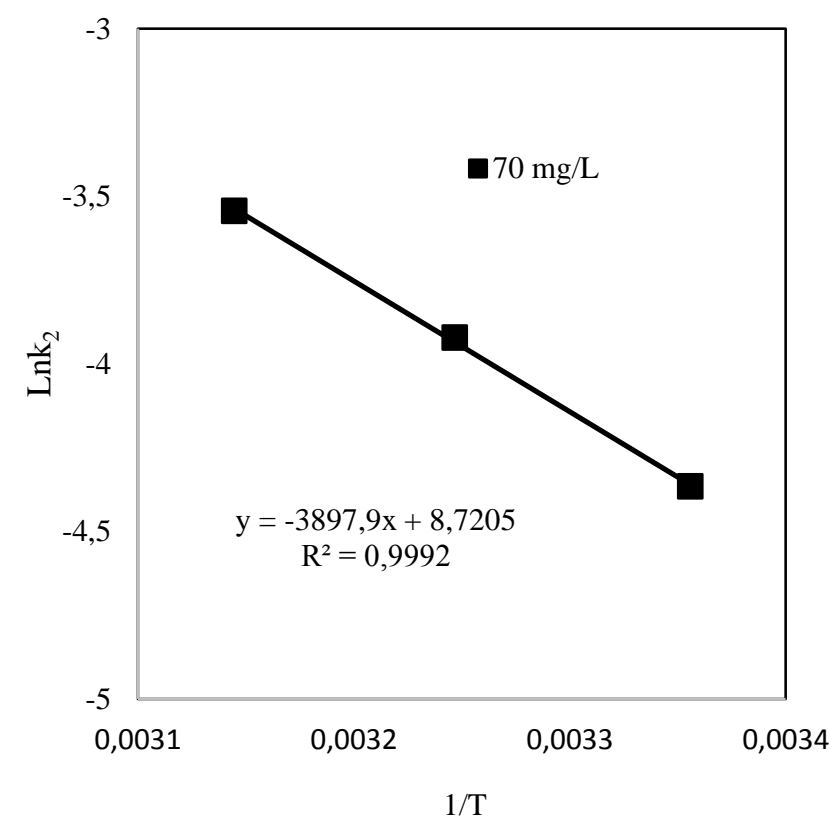

Şekil 12. $70 \mathrm{mg} / \mathrm{L} \mathrm{CV}$ konsantrasyonunda 1/T'ye karşı çizilen $\mathrm{Lnk}_{2}$ grafiği (Aktivasyon enerjisi)

Termodinamik değerlendirmeler adsorpsiyon sürecinin kendiliğinden olup olmadığına karar vermek için gereklidir. Adsorpsiyonun termodinamik parametreleri, adsorpsiyon davranışını belirlemek üzere üç farklı adsorpsiyon sıcaklığında gerçekleştirilmiştir. Gibbs serbest enerji değişimi $\left(\Delta \mathrm{G}^{\circ}, \mathrm{kJ} / \mathrm{mol}\right)$, entalpi değişimi $\left(\Delta \mathrm{H}^{\circ}, \mathrm{kJ} / \mathrm{mol}\right)$ ve entropi değişimi $\left(\Delta \mathrm{S}^{\circ}, \mathrm{kJ} / \mathrm{mol}\right)$. Bu parametreler 10 , 11 ve 12 nolu eşitlikler kullanılarak hesaplanmıştır (Guerrero-Coronilla et al., 2015; Mondal et al., 2017).

$\Delta G^{o}=-R T \operatorname{Ln} K_{c}(10)$

$K_{c}=\frac{\text { Tutulan boyar madde miktarl }(\mathrm{mg} / \mathrm{L})}{\text { Çözeltide kalan boyar madde miktarl }(\mathrm{mg} / \mathrm{L})}(11)$

$\Delta G^{o}=\Delta H^{o}-T \Delta S^{o}$

R; gaz sabiti (8.314 J/mol K) ve T; çözelti sıcaklığı(K). Eşitlik 12'den T'ye karşı çizilen $\Delta \mathrm{G}^{\mathrm{o}}$ grafiğinin (Şekil 13) eğim ve kesim noktalarından $\Delta \mathrm{S}^{\mathrm{o}}$ ve $\Delta \mathrm{H}^{\mathrm{o}}$ değerleri hesap edilmiştir. $\mathrm{CV}$ boyar maddesinin adsorpsiyonunda Gibbs serbest enerji $\Delta \mathrm{G}^{\mathrm{o}}$ değerleri (Tablo 4) bütün sıcaklıklarda negatif olarak hesaplanmıştır. $\mathrm{Bu}$ durum adsorpsiyonun kendiliğinden gerçekleştiğini, 
pozitif bulunan $\Delta \mathrm{H}^{\mathrm{o}}$ değerleri ise artış olduğunu göstermektedir. Tüm bu adsorpsiyonun endotermik olduğunu sonuçlardan, CV adsorpsiyonunun, çözelti göstermektedir (Ofomaja and Ho, 2008). sıcaklığındaki değişiklikten daha fazla Pozitif bulunan $\Delta S^{o}$ değerleri, adsorpsiyon etkilendiği sonucuna varılabilir. (Elmoubarki sirasında katı/sı1v1 ara yüzündeki rastgele bir et al., 2015)

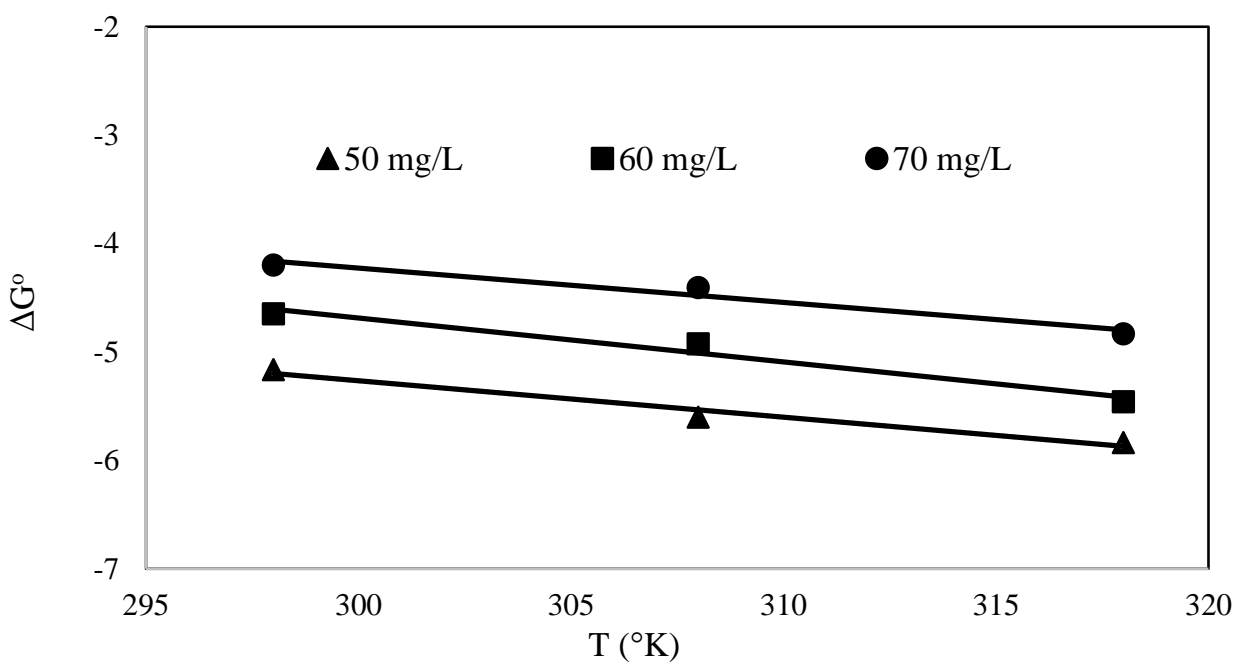

Şekil 13. CV adsorpsiyonunda $T^{\prime}$ 'ye karşı çizilen $\Delta \mathrm{G}^{\circ}$ grafiği.

Tablo 4. Buğday kepeği ile farklı konsantrasyonlarda CV boyar maddesinin adsorpsiyonunda termodinamik parametreler.

\begin{tabular}{|c|c|c|c|c|c|}
\hline \multirow[t]{3}{*}{ CV kons. $(\mathrm{mg} / \mathrm{L})$} & \multicolumn{3}{|c|}{$\underline{\Delta \mathrm{G}^{\circ}(\mathrm{kj} / \mathrm{mol})}$} & \multirow[b]{2}{*}{$\underline{\Delta H^{\circ}}(\mathbf{k j} / \mathbf{m o l})$} & \multirow{3}{*}{$\Delta \mathrm{S}^{\circ}(\mathrm{kj} / \mathrm{mol})$} \\
\hline & & & & & \\
\hline & $\underline{298 K}$ & $\underline{308 ~ K}$ & $\underline{318 K}$ & & \\
\hline 50 & $-5,164$ & $-5,603$ & $-5,836$ & 4,814 & 0,033 \\
\hline 60 & $-4,649$ & $-4,924$ & $-5,459$ & 7,463 & 0,040 \\
\hline 70 & $-4,199$ & $-4,408$ & $-4,832$ & 5,268 & 0,031 \\
\hline
\end{tabular}

\section{Sonuç}

$\mathrm{Bu}$ çalışmada etkili ve doğal bir adsorbent olan buğday kepeği, CV boyar maddesinin giderimi için adsorpsiyon çalışmalarında kullanılmıştır. Çalışma temas süresi, pH etkisi, adsorbent miktarı, boyar madde konsantrasyonu ve sicaklik parametreleri üzerinden değerlendirilmiştir. Boyar madde adsorpsiyonu ilk dakikalarda hızlı bir şekilde ilerlemiş ancak 120. dakikada dengeye gelmiştir. Adsorbent miktarı arttıkça adsorpsiyon veriminde artış görülmüştür.
Boyar madde konsantrasyonu arttıkça giderim veriminde azalma gözlemlenirken adsorpsiyon kapasitesi artmıştır. Yaklaşık \% 90 verimin elde edildiği $25{ }^{\circ} \mathrm{C}$, doğal $\mathrm{pH}$ (6.24), $50 \mathrm{mg} / \mathrm{L}$ boyar madde konsantrasyonu ve $3 \mathrm{~g} / \mathrm{L}$ adsorbent miktarı optimum değerler olarak kabul edilmiştir. Adsorpsiyondan elde edilen sonuçların Freundlich izoterm modeline ve yalancı ikinci derece eşitliğine daha iyi uyduğu belirlenmiştir. Termodinamik analizler buğday kepeği ile $\mathrm{CV}$ adsorpsiyonunun endotermik ve kendiliğinden geliştiğini göstermiştir. Sonuçlar sulu solüsyonlardan $\mathrm{CV}$ boyar 
madde giderimi için buğday kepeğinin iyi bir adsorbent olduğunu göstermektedir.

\section{Kaynaklar}

Akar, T., Ozcan, A.S., Tunali,S., Ozcan, A. 2008. Biosorption of a Textile Dye (Acid Blue 40) by Cone Biomass of Thuja Orientalis: Estimation of Equilibrium, Thermodynamic and Kinetic Parameters. Bioresource Technology, 99(8), 3057-3065.

Albadarin, A.B., Solomon, S.,Kurniawan, T.A., Mangwandi, C., Walker, G. 2017. Single, Simultaneous and Consecutive Biosorption of $\mathrm{Cr}(\mathrm{VI})$ and Orange II onto Chemically Modified Masau Stones. Journal of Environmental Management, 204, 365-74.

Bentahar, S., Dbik, A., El Khomri, M., El Messaoudi, N., Lacherai, A. 2017. Adsorption of Methylene Blue , Crystal Violet and Congo Red from Binary and Ternary Systems with Natural Clay: Kinetic, Isotherm and Thermodynamic. Journal of Environmental Chemical Engineering, 5(6), 5921-5932.

Ceylan, Z., Mustafaoglu, D., Malkoc, E. 2017. Adsorption of Phenol by MMTCTAB and WPT-CTAB : Equilibrium, Kinetic and Thermodynamic Study Adsorption of Phenol by MMT-CTAB and WPT-CTAB : Equilibrium, Kinetic and Thermodynamic Study. Particulate Science and Technology, 6351 (February), 1-11.

Dawood, S., Kanti Sen, T. 2012. Removal of Anionic Dye Congo Red from Aqueous Solution by Raw Pine and Acid-Treated Pine Cone Powder as Adsorbent: Equilibrium, Thermodynamic, Kinetics, Mechanism and Process Design. Water Research, 46(6), 1933-1946.

Elmoubarki, R., Mahjoubi, F.Z., Tounsadi, H., Moustadraf, J., Abdennouri, M., Zouhri, A., El Albani, A., Barka, N. 2015. Adsorption of Textile Dyes on Raw and Decanted Moroccan Clays: Kinetics, Equilibrium and Thermodynamics. Water Resources and Industry, 9, 16-29.
Ertugay, N. 2016. Basic Violet 10 (BV10) Removal from Aqueous Solutions Using Sawdust of Swietenia Mahagoni (Mahogany Trees): Adsorbent Characterization, Adsorption Isotherm, Kinetics, and Thermodynamic Studies. Desalination and Water Treatment, 57(26), 12335-12349.

Deniz, F. Șengül, K. 2015. Pinus Brutia Ten . (Kızılçam) Kozalak ve Yaprak Biyomasının Boya Biyosorpsiyon/ Desorpsiyon Potansiyeli. KSÜ Doğa Bilimleri Dergisi, 17(3), 19-25.

Da Fontoura, J.T., Rolim, G.S., Mella, B., Farenzena, M., Gutterres, M. 2017. Defatted Microalgal Biomass as Biosorbent for the Removal of Acid Blue 161 Dye from Tannery Effluent. Journal of Environmental Chemical Engineering, 5(5), 5076-5084.

Guerrero-Coronilla, I., Morales-Barrera, L., Cristiani-Urbina, E. 2015. Kinetic, Isotherm and Thermodynamic Studies of Amaranth Dye Biosorption from Aqueous Solution onto Water Hyacinth Leaves. Journal of Environmental Management, 152, 99-108.

Khamparia, S., Jaspal, D. 2016. Adsorptive Removal of Direct Red 81 Dye from Aqueous Solution onto Argemone Mexicana. Sustainable Environment Research, 26(3), 117-123.

Kocaer, F. O., Alkan, U. 2002. Boyar Madde İçeren Tekstil Atıksularının Arıtım Alternatifleri. Uludağ Üniversitesi Mühendislik-Mimarlık Fakültesi Dergisi, 7(1), 47-55.

Lawal, I.A., Chetty, D., Akpotu, S.O., Moodley, B. 2017. Sorption of Congo Red and Reactive Blue on Biomass and Activated Carbon Derived from Biomass Modified by Ionic Liquid. Environmental Nanotechnology, Monitoring and Management, 8(May), 83-91.

Liu, J., Wang, Z., Li, H., Hu, C., Raymer, P., Huang, Q. 2018. Effect of Solid State Fermentation of Peanut Shell on Its Dye Adsorption Performance. Bioresource Technology, 249 (October 2017), 307314. 
Mondal, N.K., Samanta, A., Dutta, S., Chattoraj, S. 2017.Optimization of $\mathrm{Cr}(\mathrm{VI})$ Biosorption onto Aspergillus Niger Using 3-Level Box-Behnken Design: Equilibrium, Kinetic, Thermodynamic and Regeneration Studies. Journal of Genetic Engineering and Biotechnology, 15(1), 151-160.

Mustafa, M.M., Jarnal, P., Alkhatip, M.F., Mahmod, S.S., Jimat, D.N., Ilyas, N.N. 2017. Panus Tigrinus as a Potential Biomass Source for Reactive Blue Decolorization: Isotherm and Kinetic Study. Electronic Journal of Biotechnology, 26, 7-11.

Ofomaja, A. E., Ho, Y.S. 2008. Effect of Temperatures and $\mathrm{pH}$ on Methyl Violet Biosorption by Mansonia Wood Sawdust. Bioresource Technology, 99(13), 5411-5417.

Oguntimein, G.B. 2015. ogunt. Journal of Environmental Chemical Engineering, 3(4), 2647-2661.

Köklü, R., Özer, Ç. 2018. Remazol Brillant Blue R (RBBR) Boyar maddesinin Düşük Maliyetli Bir Adsorban Olan Sigara Külü ile Giderimi Removal of Remazol Brilliant Blue R ( RBBR ) Dyes with a Low Cost Adsorbent, Cigarette Ash. Sakarya Üniversitesi Fen Bilimleri Enstitüsü Dergisi, 22(2), 174180.

Rangabhashiyam, S., Lata, S. Balasubramanian P. 2017. Biosorption Characteristics of Methylene Blue and Malachite Green from Simulated Wastewater onto Carica Papaya Wood Biosorbent. Surfaces and Interfaces (September), 1-19.

Omer, O.S., Hussein, M.A., Hussein, B.H. M., Mgaidi, A. 2018. Adsorption Thermodynamics of Cationic Dyes (Methylene Blue and Crystal Violet) to a Natural Clay Mineral from Aqueous Solution between 293.15 and $323.15 \mathrm{~K}$. Arabian Journal of Chemistry, 11, 615623.

Salazar-Rabago, J.J., Leyva-Ramos, R., Rivera-Utrilla, J., Ocampo-Perez, R., Cerino-Cordova, F.J. 2017. Biosorption Mechanism of Methylene Blue from Aqueous Solution onto White Pine
(Pinus Durangensis) Sawdust: Effect of Operating Conditions. Sustainable Environment Research, 27(1), 32-40.

Santos, S.C.R., Boaventura, R.A.R. 2016. Adsorption of Cationic and Anionic Azo Dyes on Sepiolite Clay: Equilibrium and Kinetic Studies in Batch Mode. Journal of Environmental Chemical Engineering, 4(2), 1473-1483.

Tang, H., Zhou, W., Zhang, L.2012. Adsorption Isotherms and Kinetics Studies of Malachite Green on Chitin Hydrogels. Journal of Hazardous Materials, 209-210, 218-225.

Wang, X. S., Liu, X., Wen, L., Zhou, Y., Jiang, Y., Li, Z. 2018. Comparison of Basic Dye Crystal Violet Removalfrom Aqueous Solution by Low-Cost Biosorbents. Separation Science and Technology, 43, 3712-3731.

Wang, K., Fu, J., Wang, S., Gao, M., Zhu, J., Wang, Z., Xu, Q. 2018.PolydopamineCoated Magnetic Nanochains as Efficient Dye Adsorbent with Good Recyclability and Magnetic Separability. Journal of Colloid and Interface Science, 516, 263-273.

Yang, J.X., Hong, G.B. 2018. Adsorption Behavior of Modified Glossogyne Tenuifolia Leaves as a Potential Biosorbent for the Removal of Dyes. Journal of Molecular Liquids, 252, 289295.

İmecik, Z., Dığrak, M., Halipçi, H.N. 2014. Safranin 'in Sulu Ortamdan Platanus Orientalis L. Biyoması Kullanılarak Giderimi. Furat Üniversitesi Fen Bilimleri Dergisi, 26(2), 139-145.

Zıba, C.A., Akarsu, S., Arslantaş, M., Dolaz, M. 2016. Tekstil Atık Sularında Renk Gidermede Kullanılan Koagulantlar: Nişasta ve CMPS'nin Floklaşmaya Etkisi. KSU. Journal of Engineering Sciences, 19(3), 110-114. 